\title{
AFIKS PEMBENTUK ADJEKTIVA DALAM BAHASA LAMPUNG \\ DIALEK A LOGAT BELALAU \\ (Analisis Morfologis)
}

\author{
Megaria \\ Program Studi Pendidikan Bahasa dan Sastra Indonesia dan Daerah \\ FKIP Universitas Lampung (Unila) \\ Pos-el: megaspd@yahoo.co.id
}

\begin{abstract}
Abstrak
Penelitian ini mengkaji tentang afiks pembentuk adjektiva dalam bahasa Lampung dialek A logat Belalau yang disingkat (BLA). Analisis dalam penelitian terdiri atas prefiksasi, sufiksasi, infiksasi, dan konfiksasi. Metode yang digunakan adalah metode deskriptif kualitatif. Data berasal dari telaah pustaka, khususnya teks yang menggunakan bahasa Lampung Dialek A dan sebagian berasal dari tuturan lisan yang berfungsi sebagai pelengkap data. Hasil penelitian menunjukkan bahwa afiks pembentuk adjektiva dalam BLA terdiri atas (1) prefiks, (2) sufiks, (3) konfiks, dan (4) kombinasi afiks. Prefiks pembentuk adjektiva dalam BLA terdiri atas prefiks $s e$-, dan te-. Sufiks dalam BLA hanya satu, yakni sufiks -an. Afiks lainnya adalah konfiks ke-an dan kombinasi afiks.
\end{abstract}

Kata kunci: morfologi, afiksasi, adjektiva, bahasa Lampung .

\section{ADJECTIVE AFFIXES IN LAMPUNGESE A LOGAT BELALAU DIALECT}

\begin{abstract}
This research examines the adjective affixes in Lampungese, focusing on A Belalau Logat dialect. The analysis of this study consists of prefixes, suffixes, infixes, and confixes. This study employed a descriptive qualitative method. The main data came from the existing literature, especially the text in the dialect in question and the complementary data came from oral speech of Lampung native speakers. This study showed that the adjective affixes in Lampungese comprise (1) prefixes, (2) suffixes, (3) confixes, and (4) affix combinations. The prefixes include the prefix se-and te-. The suffix observed is only the suffix-an. In addition, there exists the confix ke-an as well as the combination of affixes.
\end{abstract}

Key words: morphology, affix, adjective, Lampungese.

\section{PENDAHULUAN}

Bahasa Lampung termasuk salah satu bahasa daerah yang terdapat di Indonesia. Bahasa ini digunakan oleh masyarakat Lampung untuk berkomunikasi sehari-hari baik dalam lingkungan keluarga masyarakat Lampung maupun upacara adat. Bahasa Lampung termasuk kelas Austronesia dalam keluarga bahasa Melayu Polinesia, memiliki dua dialek yang hidup berdampingan dan keduanya aktif digunakan oleh masing-masing masyarakat pengguna dialek tersebut. Dialek yang dimaksud yaitu, dialek A (api) dan dialek $\mathrm{O}$ (nyou) yang kedua mengacu pada kata 'apa'. Hadikusumah (1994:7) menyatakan dialek A sebagai dialek Pubian dan dialek O sebagai dialek Abung, sedangkan Walker membagi bahasa Lampung menjadi dialek Abung dan dialek Pesisir (Sanusi: 2003:4). 
Perbedaan pendapat dari para pakar mengenai nama dialek sebenarnya memiliki maksud yang sama, yaitu mengacu pada dialek A dan dialek $\mathrm{O}$.

Berdasarkan peta bahasa, pemakai bahasa Lampung dialek A meliputi masyarakat: (1) Melinting, (2) Maringgai, (3) Pesisir Rajabasa, (4) Pesisir Teluk, (5) Pesisir Semaka, (6) Pesisir Krui, (7) Belalau,(8) Ranau, (9) Komering, dan (10) Kayu Agung, sedangkan dialek $\mathrm{O}$ dipakai oleh masyarakat Abung dan Menggala/Tulang Bawang. Bahasa Lampung Dialek A logat Belalau digunakan oleh suku Lampung yang berdomisili di (1) Kabupaten Lampung Barat, meliputi: Kecamatan Balik Bukit, Batu Brak, Belalau, Suoh, Sukau, Ranau, Sekincau, Gedung Surian, Way Tenong dan Sumber Jaya; (2) Kabupaten Lampung Selatan meliputi: Kecamatan Kalianda, Penengahan, Palas, Pedada, Katibung, Way Lima, Padangcermin, Kedondong, dan Gedongtataan; (3) Kabupaten Tanggamus meliputi: Kecamatan Kotaagung, Semaka, Talangpadang, Pagelaran, Pardasuka, Hulu Semuong, Cukuhbalak dan Pulau Panggung; (4) Kota Bandar Lampung meliputi: Teluk Betung Barat, Teluk Betung Selatan, Teluk Betung Utara, Panjang, Kemiling, dan Raja Basa.

Bahasa Lampung tidak mengenal tingkatan ngoko dan kromo seperti dalam bahasa Jawa, tetapi bahasa Lampung menggunakan ragam berbahasa seperti ragam resmi dan ragam nonresmi (Sanusi, 2003: 4). Sebagai contoh, dalam bahasa Lampung dialek A logat Belalau untuk mengungkapkan hubungan antarpembicara dalam ragam resmi menggunakan nyakku 'saya', sikam ghuppok 'kami', kutti ghuppok 'kalian'. Hal ini, berbeda dengan ragam nonresmi atau ragam lisan yang menggunakan nyak 'saya', sikam 'kami', kutti 'kalian'.

Bahasa Lampung dialek A logat Belalau (BLA) memiliki kelas kata yang sama dengan bahasa Indonesia, seperti verba, nomina, adjektiva, dan adverbia.
Secara morfologis adjektiva BLA terdiri dari adjektiva dasar (monomorfemis) dan adjektiva turunan (polimorfemis). Adjektiva dasar berasal dari kelas adjektiva dasar yang bersifat monomorfemis dan tergolong morfem bebas, misalnya pacak 'pintar', ghayang ' kurus', liyom 'malu', sedangkan adjektiva turunan dibentuk dengan melalui (1) pembubuhan afiks, (2) reduplikasi, dan (3) pemajemukan.

Menurut Kridalaksana (2001:3) afiks adalah bentuk terikat yang apabila ditambahkan pada bentuk lain akan mengubah makna gramatikalnya. Konsep ini mencakup prefiks, sufiks, infiks, simulfiks, konfiks, dan suprafiks. Putrayasa (2008:5) menyatakan afiksasi merupakan pembentukan kata dengan membubuhkan afiks (imbuhan) pada bentuk dasar, baik bentuk dasar tunggal maupun kompleks.

Adjektiva berafiks dalam BLA dapat dibentuk melalui proses pemberian afiks baik pada awal (prefiks), akhir (sufiks), dan awal serta akhir (konfiks), misalnya prefiks te- yang berfungsi membentuk makna 'superlatif', seperti pada contoh berikut ini.

$\begin{aligned} & \text { te-+ kejung 'panjang' } \rightarrow \begin{array}{l}\text { tekejung } \\ \text { 'menjadi lebih } \\ \text { panjang' }\end{array} \\ & \text { te-+ pelik 'sempit' } \rightarrow \begin{array}{l}\text { tepelik } \\ \text { 'menjadi lebih } \\ \text { sempit' }\end{array}\end{aligned}$

Sufiks -an dalam BLA berfungsi membentuk makna 'komparatif', misalnya

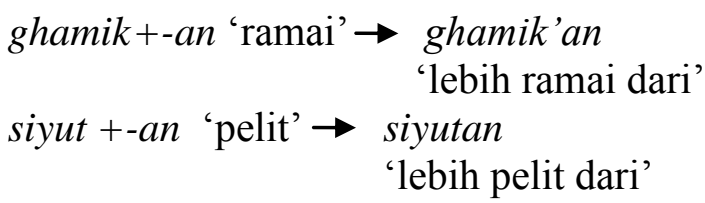

Konfiks ke-an dalam BLA berfungsi membentuk makna superlatif, yakni dengan cara membubuhkan konfiks ke-an pada adjektiva dasar, misalnya

$$
\begin{array}{cc}
\text { ke-+ kelom }+ \text {-an } \rightarrow & \begin{array}{c}
\text { kekeloman } \\
\text { 'terlalu gelap' }
\end{array} \\
\text { ke-+ lunik+ -an } \rightarrow \begin{array}{c}
\text { kelunik'an } \\
\text { 'terlalu kecil' }
\end{array}
\end{array}
$$


Adjektiva turunan yang dibentuk melalui proses reduplikasi dan pemajemukan tidak peneliti bahas lebih mendalam, sebab penelitian ini difokuskan pada afiks pembentuk adjektiva dalam BLA.

Sanusi (2003:104) dan Udin dkk. (1992:49) mengungkapkan ciri-ciri sintaksis adjektiva BLA secara terperinci, yaitu (1) dapat diingkari dengan kata ingkar mak yang berarti 'tidak' misalnya mak melamon 'tidak banyak', (2) adjektiva dapat diberi keterangan 'superlatif', seperti paling 'paling', temon atau nihan 'sekali/benar', misalnya balak nihan 'besar sekali', (3) adjektiva dapat diikuti oleh morfem terikat $g a$ 'terlampau', misalnya lunikga 'terlampau kecil', (4) adjektiva dapat diberi kata ingkar mati 'alangkah', misalnya mati cuttikna 'alangkah sedikitnya', (5) adjektiva dapat diberi keterangan pembanding lebih 'lebih', kughang 'kurang', paling 'paling', (6) adjektiva dapat menduduki fungsi predikat dalam klausa nominal, misalnya buwokna keghiting 'rambutnya keriting'.

Berdasarkan pengamatan peneliti yang bersumber dari telaah pustaka dan tuturan lisan, dapat disimpulkan terdapat ciri lain untuk mengungkapkan kekhasan adjektiva BLA sebagai pembeda dari kelas kata lainnya, yaitu (1) frasa adjektiva dapat ditandai adverbia sai 'yang', misalnya Sanak sai lunik 'anak yang kecil', (2) bentuk Imperatif ditandai dengan sufiks ko/kon 'kan', misalnya lunikko/kon 'kecilkan', (3) bentuk introgatif ditandai dengan kudo 'kah' di belakang adjektiva dasar, misalnya mesikop kudo 'cantikkah', melamon kudo 'banyakkah', (5) bentuk superlatif selain morfem terikat ga, nihan atau temon terdapat juga bentuk lain, seperti baccong/ighih 'sangat'.

Adjektiva BLA ditinjau dari segi perilaku semantis terdiri atas (1) adjektiva pemeri sifat, misalnya bakkang 'kosong', behgassih 'bersih'; (2) adjektiva ukuran misalnya benni 'lama', kejang 'panjang'; (3) adjektiva warna, misalnya halom 'hitam', suluh 'merah'; (4) adjektiva sikap batin misalnya ghabai 'takut';(5) adjektiva cerapan, misalnya maghum 'harum, kelom 'gelap' (Sanusi, 2003:110). Pembagian adjektiva dalam BLA sama halnya dengan adjektiva bertaraf dalam bahasa Indonesia yang menurut Alwi dkk. (2003:172) terdiri atas (1) adjektiva pemeri sifat, (2) adjektiva ukuran, (3) adjektiva warna, (4) adjektiva waktu, (5) adjektiva jarak, (6) adjektiva sikap batin, dan (7) adjektiva cerapan.

Penelitian ini difokuskan pada adjektiva berafiks dalam BLA. Hal yang menjadi kajian adalah bentuk adjektiva turunan (polimorfemis) yang dibentuk oleh afiks yang meliputi prefiks, sufiks, dan konfiks.

\section{METODE}

Penelitian ini menelaah tentang adjektiva berafiks dalam BLA, metode penelitian yang digunakan adalah metode deskriptif dengan pendekatan kualitatif. Metode deskriptif digunakan untuk mendeskripsikan afiks pembentuk adjektiva yang terdiri dari prefiks, sufiks, dan konfiks. Metode merupakan cara kerja yang teratur, terpikir baik-baik, dan bersistem untuk memudahkan pelaksanaan suatu kegiatan guna mencapai suatu tujuan yang telah ditentukan (Djajasudarma, 2006:1). Penelitian ini menggunakan metode deskriptif kualitatif untuk menganalisis afiks pembentuk adjektiva dalam BLA.

Sumber data dalam penelitian ini berasal dari data tertulis (telaah pustaka) dan data lisan (responden). Metode kajian yang digunakan menggunakan kajian distribusional, yaitu kajian yang menggunakan alat penentu unsur bahasa itu sendiri (Djajasudarma, 2006:69).

\section{HASIL DAN PEMBAHASAN}

Adjektiva BLA terdiri dari adjektiva dasar yang bersifat monomorfemis dan adjektiva turunan yang bersifat polimorfemis. Kajian dalam penelitian ini hanya akan membahas tentang adjektiva turunan yang dibentuk melalui proses afiksasi. Dalam pembahasan ini digunakan 
teori pembentukan kata oleh Kridalaksana (1994) yang membagi afiks pembentuk adjektiva menjadi prefiks, infiks, sufiks, kombinasi afiks, dan konfiks.

Adjektiva dalam BLA dapat dibentuk dengan cara membubuhan afiks pada adjektiva dasar yang meliputi: (1) prefiks, (2) sufiks, (3) konfiks, dan (4) kombinasi afiks. Setiap afiks akan dibahas dalam paparan berikut ini.

\section{Prefiks}

Prefiks pembentuk adjektiva dalam BLA terdiri dari prefiks se-, dan te-. Berikut ini diuraikan pembentukan adjektiva yang mendapat prefiks.

\section{1) Prefiks se-}

Adjektiva BLA berprefiks se-dapat dibentuk dengan dua cara, yaitu (a) membubuhkan prefiks se- pada adjektiva dasar dan (b) membubuhkan afiks se-R-na pada adjektiva dasar.

Prefiks se- dibentuk dengan cara menambahkan prefiks $s e$ - pada adjektiva dasar. Prefiks se- berfungsi memberi makna gramatikal 'sama atau seperti', misalnya

se-+ $\left\{\begin{array}{lll}\text { helau } & \text { 'bagus' } \rightarrow \text { sehelau } & \text { 'sebagus' } \\ \text { sikop } & \text { 'cantik' } \rightarrow \text { sesikop } & \text { 'secantik' } \\ \text { ghamik } & \text { 'ramai' } \rightarrow \text { seghamik } & \text { 'seramai' } \\ \text { ghedik } & \text { 'dekat' } \rightarrow \text { seghedik } & \text { 'sedekat' } \\ \text { ghanggal } & \text { 'tinggi' } \rightarrow \text { seghanggal } & \text { 'setinggi' }\end{array}\right.$

Afiks ini tergolong ke dalam afiks yang produktif dalam BLA, baik digunakan dalam ragam lisan maupun ragam tulisan. Contoh kalimat

Abang jo ghadu seghanggal bakna.

'Kakak sudah setinggi bapaknya.'

Jamma sai ghatong mid pekan mawatk hak seghamik nambi.

'Orang yang datang ke pasar tidak seramai kemarin.'

Kawai sai kubeli mawat hak sehelau kawaimu.

'Baju yang saya kubeli tidak sebagus bajumu.'
Adjektiva turunan dalam BLA dapat dibentuk dengan cara lain, yakni dengan cara membubuhkan afiks se- $R-n a$ yang dilekatkan pada bentuk dasar yang berupa kelas kata adjektiva. Fungsi afiks ini membentuk makna gramatikal yang menyatakan 'perbandingan komparatif', misalnya

se-+ghabai-ghabai $+n a$
se-+ghamik-ghamikna $\rightarrow$ 'setakut-takutnya'
se-+lamon-lamonna $\rightarrow$ 'seramai-ramainya'
se-+ ghisok-ghisokna $\rightarrow$ 'sebanyak-banyaknya'
se-+liyom-liyomna $\rightarrow$ 'sesering-seringnya'

Pemakaian afiks se- $R$-na dalam kalimat menggunakan kata jak ' lebih' atau kidang 'tetapi' sebagai pembanding komparatif. Hal ini dapat dirumuskan menjadi

se- R-na..., jak... atau $s e-R$-na...,kidang...

Contoh kalimat

Seliyom-liyomku ghani hijjo jak ki liyomku pas nyak nigacci bakku.

'semalu-malunya saya hari ini, lebih malu lagi ketika dimarahi ayahku'.

Seghabai-ghabaiku jama mak, jak ki ghabaiku jama bak.

'setakut-takutnya saya dengan ibu, akan lebih takut lagi kepada ayah.'

Seghamik-ghamikna jamma sai ghatong, kidang tetop mangi mana niku mak ghatong. 'seramai-ramainya tamu yang datang, tetapi tetap sepi karena kamu tidak datang.'

Pemakaian afiks se- $R$-na merupakan afiks yang digunakan dalam ragam percakapan dan termasuk ke dalam afiks yang nonproduktif digunakan dalam ragam tulis.

\section{2) Prefiks te-}

Adjektiva dalam BLA dapat dibentuk dengan cara menambahkan prefiks te- pada kata dasar yang berkelas adjektiva. Prefiks te- dalam BLA tidak memiliki alomorf 
seperti halnya bahasa Indonesia. Prefiks ini berfungsi untuk menekankan makna superlatif 'menjadi lebih'. Pemakaian afiks ini tergolong ke dalam afiks yang produktif dalam BLA baik dalam ragam lisan maupun ragam tulis, misalnya

te-+\{ $\begin{aligned} & \text { Handak 'putih' } \rightarrow \text { 'tehandak' 'lebih putih', } \\ & \text { Ghayang 'kurus' } \rightarrow \text { 'teghayang' 'lebih kurus' } \\ & \text { ghanggal 'tinggi' } \rightarrow \text { 'teghanggal' 'lebih tinggi' } \\ & \text { teghamik 'ramai' } \rightarrow \text { 'teghamik' 'lebih ramai', } \\ & \text { tehalom 'hitam' } \rightarrow \text { tehalom' 'lebih hitam' }\end{aligned}$

Contoh kalimat

Tehandak niku tanno semula jak Bandarlampung.

'Kamu sekarang lebih putih semenjak di Bandarlampung'.

Adek jo ghadu teghanggal tanno semula jak ti sunat so.

'Adik sudah lebih tinggi sekarang semenjak disunat.

Niku jadi teghayang semula jawoh jak hulun tuha.

'Kamu lebih kurus semenjak jauh dari orang tua'.

\section{3) Sufiks -an}

Adjektiva BLA mengenal sufiks -an, pembubuhan sufiks -an dibentuk dengan cara menambahkan sufiks -an pada kata dasar yang berkelas adjektiva. Sufiks -an berfungsi membentuk makna gramatikal 'perbandingan komparatif', misalnya

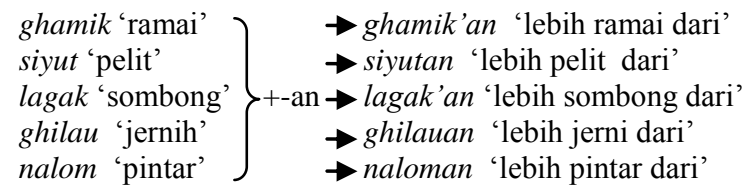

Pemakaian sufiks -an dalam kalimat menggunakan kata jak 'lebih' sebagai pembanding komparatif. Hal ini dapat dapat dirumuskan

Adjektiva+ -an...jak...
Contoh kalimat

Siyutan ngahmu jak Abangmu.

'Lebih pelit kakak perempuanmu daripada Abangmu'.

Naloman Abang jak Adek jo.

'Lebih pintar Abang daripada adik.'

Ghilauan wai labung jak ki wai jak ledeng.

'lebih jernih air hujan daripada air ledeng.'

Penggunaan sufiks -an tergolong ke dalam afiks yang kurang produktif dalam BLA, afiks ini kerap digunakan dalam ragam percakapan dan jarang sekali ditemukan dalam ragam lisan.

\section{4) Konfiks ke-an}

Adjektiva berkonfiks ke-an dalam BLA dibentuk dengan cara menambahkan konfiks ke-an pada kata dasar yang berkelas adjektiva. Fonem awal pada adjektiva dasar yang telah dibubuhi konfiks $k e$-an tidak mengalami proses morfofonemis dan tidak ada perubahan kelas kata (derivasi). Konfiks ke-an berfungsi membentuk makna gramatikal superlatif 'terlalu' jika diletakkan pada kata dasar yang berkelas adjektiva.

Penggunaan konfiks ke-an tergolong ke dalam afiks yang produktif digunakan oleh penutur BLA baik dalam ragam lisan/percakapan maupun ragam tulisan, misalnya

$\mathrm{ke-+-an}\left\{\begin{array}{l}\text { manom'sore' } \rightarrow \text { kemanoman 'terlalu sore' } \\ \text { hasin 'asin' } \rightarrow \text { kehasinan 'terlalu asin' } \\ \text { pelik'sempit' } \rightarrow \text { kepelik'an'terlalu sempit' } \\ \text { lamon'banyak' } \rightarrow \text { kelamonan 'terlalu banyak' } \\ \text { latap'penuh' } \rightarrow \text { kelatapan 'terlalu penuh' }\end{array}\right.$

Contoh kalimat

Minah sakik tenai mana kelamonan nganik mangga.

'Mina sakit perut karena terlalu banyak makan mangga.'

Kawai ni Mamak saghak pas ni pakaina mana ghadu kepelik'an.

'Baju Paman robek saat dipakai karena sudah terlalu sempit.' 
Gulai jo kehasinan mana lamon ga tikeni uyah.

'Sayur ini terlalu asin karena terlalu banyak diberi garam.'

\section{5) Kombinasi Afiks}

Dalam BLA ditemukan adjektiva yang dibentuk dengan cara mengombinasi afiks pada kata dasar yang berkelas adjektiva. Jenis kombinasi afiks pembentuk adjektiva terdiri dari: (a) pembubuhan afiks pu-R, dan (b) adjektiva yang dibentuk melalui reduplikasi parsial $+-a n$.

\section{Kombinasi Afiks pu-R}

Adjektiva BLA yang dibentuk melalui kombinasi afiks $p u-R$ dilakukan dengan cara membubuhkan prefiks $p u$ - pada kata dasar yang berkelas adjektiva. Proses pembentukan afiks ini dilakukan dengan cara menambahkan prefiks $p u$ - pada adjektiva dasar yang telah mengalami proses reduplikasi utuh. Prefiks puberfungsi 'menegaskan sifat yang tersebut pada bentuk dasar'. Afiks ini tergolong ke dalam afiks yang nonproduktif baik dalam ragam lisan maupun ragam tulisan, misalnya

$$
\text { pu-+ }\left\{\begin{array}{l}
\text { ghamik-ghamik } \rightarrow \text { pukhamik-khamik'ramai- } \\
\text { ramai' } \\
\text { simah-simah } \rightarrow \text { pusimah-simah 'royal' } \\
\text { bangik-bangik } \rightarrow \text { pubangik-bangik 'enak-enak' } \\
\text { ghisok-ghisok } \rightarrow \text { pughisok-ghisok 'sering-sering' } \\
\text { pahik-pahik } \rightarrow \text { pupahik-pahik'pahit-pahit' }
\end{array}\right.
$$

Contoh kalimat

Anakni alak Nasir do puwaya-waya.

'Anaknya Paman Nasir ramah-ramah.'

Buak sai nijual ngah no pubangik-bangik.

'Kue yang dijual kakak enak-enak.'

Pukhamik-khamik tian sai nutuk mid nayuhni Lidya no.

'Mereka ramai-ramai datang ke pesta pernikahan Lidya.'

\section{Reduplikasi parsial + - an}

Adjektiva turunan dalam BLA dapat dibentuk melalui reduplikasi parsial + - an . Afiks ini dibentuk dengan cara mengulang suku kata pertama pada kata dasar yang berkelas adjektiva, selanjutnya ditambahkan sufiks - an pada kata dasar tersebut. Proses pembentukan afiks bereduplikasi parsial terlihat seperti di bawah ini.

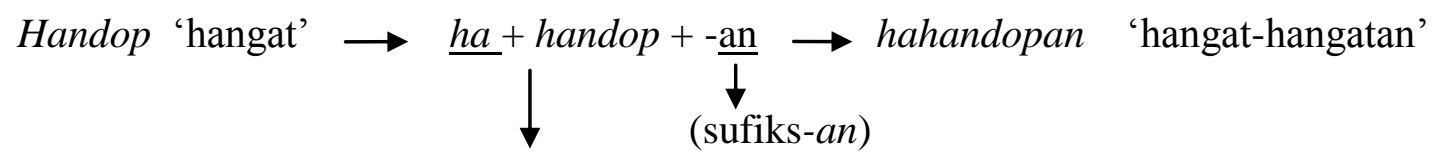

(Reduplikasi parsial)

Contoh lain:

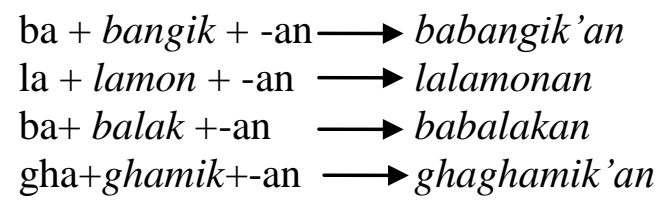

'enak-enakan'

'banyak-banyakan

'besar-besaran'

'ramai-ramai'
Dalam pembentukan afiks ini, reduplikasi selalu terjadi di depan suku kata pertama adjektiva dasar. Akan tetapi, reduplikasi parsial tidak akan memiliki makna gramatikal tanpa adanya sufiks -an. Dengan demikian, sufiks -an dalam afiks ini berfungsi untuk membentuk adjektiva yang menyatakan 'intensitas dengan arti lebih. Secara gramatikal afiks reduplikasi parsial +-an membentuk adjektiva turunan yang bermakna reduplikasi. Akan tetapi, dalam pemakainnya afiks ini tergolong kurang produktif khususnya dalam ragam tulis. Afiks ini kerap hanya digunakan dalam ragam lisan. Contoh kalimat

Sikam lagi babangik'an marok pas kutti ghatong. 
'kami masih enak-enakan ngobrol saat kalian datang.'

Sikam hak lalamonan nyunjong dibi sinji.

'Kami banyak-banyak masak nasi sore ini.

Nyak makai kawai hijjo, nyin lalagak'an gawoh.

'saya memakai baju ini supaya gaya-gayaan saja'

\section{SIMPULAN}

Satuan lingual berkategori adjektiva dalam (BLA) memiliki ragam afiks pembentuk adjektiva yang hampir sama dengan bahasa Indonesia. Berdasarkan analisis pada pembahasan mengenai afiks pembentuk adjektiva dalam BLA dapat disimpulkan bahwa, afiks pembentuk adjektiva dalam BLA terdiri dari prefiks, sufiks, konfiks, dan kombinasi afiks.

Prefiks pembentuk adjektiva dalam BLA terdiri dari prefiks se- dan tePrefiks $s e$ - berfungsi membentuk makna gramatikal 'sama atau seperti', serta berfungsi membentuk 'perbandingan tingkat komparatif'. Sufiks dalam BLA hanya satu, yakni sufiks -an yang berfungsi membentuk makna gramatikal 'perbandingan komparatif'. Konfiks ke-an berfungsi membentuk makna gramatikal superlatif 'terlalu'. Kombinasi afiks terdiri dari kombinasi afiks pu- $R$ dan Reduplikasi parsial $+-a n$. Afiks pu- $R$ berfungsi untuk 'menegaskan sifat yang tersebut pada bentuk dasar' dan Reduplikasi parsial + an. Sufiks -an berfungsi membentuk adjektiva yang menyatakan 'intensitas dengan arti lebih.'

Semua afiks pembentuk adjektiva dalam BLA dibentuk dari kata dasar yang berkelas adjektiva. Penggunaan afiks-afiks tersebut tidak semuanya produktif, afiks yang produktif adalah semua prefiks ( $s e$ dan te-), sufiks (-an), konfiks (ke-an), sementara afiks yang jarang digunakan adalah reduplikasi parsial+-an. Afiks yang tidak dipakai adalah kombinasi afiks pu-+ R.

\section{PUSTAKA RUJUKAN}

Alwi, H. dkk. (2003). Tata Bahasa Baku Bahasa Indonesia. Jakarta: Balai Pustaka.

Djajasudarma, T. F. (2006). Metode Linguistik. Bandung: Refika Aditama.

Hadikusuma, H. H.(1994). Bahasa Lampung. Jakarta: Fajar Agung.

Kridalaksana, H. (2001). Kamus Linguistik. Jakarta: Gramedia.

Kridalaksana, H.(1994). Pembentukan Kata dalam Bahasa Indonesia. Jakarta: Gramedia.

Putrayasa, I. B. (2008). Kajian Morfologi (Bentuk Derivasional dan Infleksional). Bandung: Refika Aditama.

Udin, N. dkk. 1992. Tata Bahasa Bahasa Lampung Dialek Pesisir. Jakarta: Pusat Pembinaan dan Pengembangan Bahasa Departemen Pendidikan dan Kebudayaan.

Sanusi, E. (2003). Morfologi Bahasa Lampung. Lampung: Universitas Lampung.

\section{UCAPAN TERIMA KASIH}

Puji syukur atas hidayah yang telah Allah swt limpahkan kepada peneliti, sehingga artikel ini dapat diselesaikan dengan baik. Ucapan terima kasih disampaikan kepada semua pihak yang telah membantu baik dalam pengumpulan data, maupun dalam proses penganalisisan artikel ini. Semoga artikel ini bermanfaat bagi keragaman kajian linguistik dan kepada pemerhati bahasa Lampung khususnya. Kritik dan saran yang membangun peneliti harapkan demi sempurnanya tulisan ini. 